\title{
Editorial
}

\section{Expanding the evidence for population mental health in Canada: a call to action for evidence-informed policy and practice}

\author{
Katholiki Georgiades, PhD
}

(Published online 27 September 2021)

Tweet this article

Now, well into our second year of the global COVID-19 pandemic, concerns for population mental health are mounting. These concerns are well justified given the increases in established risk factors known to contribute to mental ill-health, including economic hardship, social deprivation and cumulative losses of fundamental health and social services. The distribution and impact of these risk factors will likely be unequal, disproportionately affecting individuals living in adverse socioeconomic circumstances and marginalized communities, as well as those with pre-existing physical, mental health and neurodevelopmental conditions.

While evidence on the mental health impacts of the pandemic is accumulating rapidly, most studies to date rely on nonprobability-based sampling methods, crosssectional study designs, limited assessment of mental health and underrepresentation of marginalized populations and communities - the very populations disproportionately impacted by the pandemic. ${ }^{1-3}$ These methodological weaknesses limit generalizability, statistical inferences and attributions of pandemic-related impacts on population mental health, compromising opportunities for informing mental health policy and practice.

This special issue of Health Promotion and Chronic Disease Prevention in Canada: Research, policy and practice presents results from the 2020 Survey on COVID-19 and Mental Health (SCMH) ${ }^{4}$ a populationbased, cross-sectional survey explicitly designed to address several of the methodological weaknesses of existing evidence.
The 2020 SCMH applied robust, probability-based sampling methods to ascertain a representative sample of adults aged 18 years or older living in Canada's 10 provinces and three territorial capital cities. The sample includes 14689 respondents (53.3\% response rate) who completed an online or telephone survey during the second wave of the COVID-19 pandemic, between September and December 2020. Select survey content and measurement was similar to the annual component of the Canadian Community Health Survey (CCHS), ${ }^{5}$ a biennial, cross-sectional health survey of the Canadian population, permitting comparisons of mental health before and during the COVID-19 pandemic.

The articles ${ }^{6-10}$ in this special issue present urgently needed and reliable populationlevel estimates of mental health during the pandemic as well as comparative analyses quantifying the magnitude and distribution of change in mental health across the population and for select sociodemographic subgroups. Results are extended further by identifying correlates of mental health that are unique to the pandemic, thereby providing greater insights to inform strategies for response, recovery and future preparedness.

The findings generally converge on several important themes consistent with population-based surveys in the United Kingdom $^{11,12}$ and the United States, ${ }^{13-15}$ and systematic reviews of emerging evidence. ${ }^{16-18}$ First, levels of distress, measured using well-validated symptom-based screening instruments of depression and anxiety, have increased during the pandemic relative to before..$^{911-17}$ These increases are generally more pronounced during lockdowns compared to when pandemic restrictions ease. ${ }^{9,12,16}$

Second, increases in levels of distress vary across population subgroups and are more pronounced among younger adults, females and immigrant populations. ${ }^{9,11,13-15}$ Changes in mental health as a function of socioeconomic circumstances are nuanced: some indicators suggest a positive association between educational attainment and greater increases in levels of distress and alcohol use during the pandemic, relative to before; $;^{9,7,10}$ while other findings indicate no difference. ${ }^{8}$

Third, the prevalence of self-reported suicidal ideation appears not to have increased during the pandemic. ${ }^{8}$ These findings are consistent with recent analyses of data from 21 countries documenting no significant increase in risk of suicide in the early months of the pandemic (AprilJuly 2020) compared to expected levels based on data from the pre-pandemic period. ${ }^{19}$

Fourth, a sizable portion of the Canadian population have reported increases in cannabis (5\%) and alcohol use (16\%) since the start of the pandemic and use of either cannabis or alcohol is strongly associated with co-occurring levels of distress. ${ }^{10}$

Finally, frontline workers and individuals reporting pandemic-related economic, health and interpersonal stressors are more likely 
to report high levels of distress and suicidal ideation during the pandemic. ${ }^{8,9}$

Taken together, these findings suggest a likely increase in demand for mental health care in the population and a need for responses targeting select subgroups that have been disproportionately impacted. To bridge the gap between level of need in the population and mental health service availability, innovative models of service delivery designed to increase access and efficiency, such as stepped care and collaborative care models, may show promise. $^{20-23}$ An integral component of these efforts must include outcome monitoring to determine the effectiveness of mental health care and establish iterative cycles of continuous improvement and innovation. ${ }^{24}$

While these findings provide initial insights into potential pandemic-related impacts on population mental health, important gaps remain. First, and foremost, is the complete absence of comparable, nationally representative data on the mental health of Canadian children and young people-a longstanding gap that predates the pandemic. This is a particular concern now, given the extraordinary challenges and disruptions to fundamental aspects of their daily lives that children and young people have endured throughout the pandemic.

The mental health-related impacts of these disruptions remain largely unknown, leaving decision makers and service providers with little evidence to draw upon when deciding about allocating vital resources and establishing intervention and mitigation strategies. Without these data, policy and practice decisions cannot be adequately informed and widening mental health disparities will likely ensue.

Second, the sole reliance on crosssectional studies, with varying sampling and measurement methodologies, compromises the validity of temporal comparisons and places strict limits on causal attributions linked specifically to pandemicrelated impacts. Longitudinal studies, with comparable pre-pandemic baseline data and carefully timed follow-up assessments, are required to identify subgroups most at risk and determine temporal ordering of associations that can inform causal attributions and optimize the effectiveness of prevention and intervention strategies. ${ }^{1-3,25}$
Moreover, our current evidence of pandemic-related impacts on population mental health is restricted to the first and second waves of the pandemic. Repeated follow-up assessments are needed to monitor longer-term impacts given well-documented health consequences of previous economic recessions and disasters-particularly increasing rates of mental illhealth, including suicide and substance use as well as family violence and psychiatric hospitalizations. ${ }^{26-28}$

Third, systematic underrepresentation of marginalized, racialized and Indigenous populations creates stark data gaps that must be addressed if we are truly committed to reducing health disparities in Canada.

Fourth, mental health measurement must go beyond the use of symptom-based screening scales to include indicators of severity, comorbidity and functional impairments. ${ }^{24}$ Taking a more comprehensive approach to measurement will aid in determining who is most in need of mental health interventions.

The pandemic has shone a light on our illpreparedness for monitoring population mental health, particularly among the most vulnerable. Sustained investments in methodologically rigorous, longitudinal, population-based surveys can serve as a common platform for achieving a number of complementary goals of public health surveillance, mental health science, policy and practice. In times of crises, these surveys serve an essential role in generating timely evidence about population mental health needs, strategies for mitigating risks and opportunities for evaluating intervention efforts. ${ }^{29}$

Although costly to implement, the value proposition of longitudinal, populationbased surveys is immense, by way of generating accurate and reliable evidencenecessary prerequisites for informing mental health policy and practice. ${ }^{1,2}$ The potential of such investments is epitomized by the COVID-19 Longitudinal Health and Well-being National Core Study in the United Kingdom, which was designed to link over 20 longitudinal, population-based cohort studies with national electronic health, education, occupation and geographical records to determine the impacts of the COVID-19 pandemic in the immediate, medium and longer term. ${ }^{30}$

With mental disorders now among the leading causes of disability burden globally, there is no doubt we must increase investments in mental health science to reduce the burden of suffering. ${ }^{31}$ Policy makers and practitioners need timely evidence to inform the range of effective mental health programming required across the population and to implement layered approaches to "proportionate universalism" addressing longstanding equity goals while making effective use of public resources. $^{32} \mathrm{~A}$ critical gap that must be addressed immediately is the lack of nationally representative data on the mental health needs of Canadian children and young people. Recent investments in a longitudinal follow-up of the Canadian Health Survey of Children and Youth $(\mathrm{CHSCY})^{33}$ represent a promising starting point. The CHSCY is a nationally representative sample of children and youth aged 1 to 17 years that uses data collected by Statistics Canada immediately prior to the pandemic.

The COVID-19 pandemic represents a call to action for sustained investments in population-based, longitudinal surveys of mental health. Without such investments, we have no metric for monitoring our progress and collective impact in reducing the burden of mental ill-health in our population.

\section{Acknowledgements}

The author would like to thank Drs Charlotte Waddell, Harriet MacMillan, Peter Szatmari, Stelios Georgiades, Tracy Vaillancourt, Amanda Sim, Jordan Edwards and Christine Rodriguez and Ruth Repchuck for their critical review of the editorial. Dr. Kathy Georgiades is supported by the David R. (Dan) Offord Chair in Child Studies.

\section{Conflicts of interest}

The author declares that she has no conflicts of interest.

\section{Statement}

The content and views expressed in this editorial are those of the author and do not necessarily reflect those of the Government of Canada. 


\section{References}

1. Patten SB, Kutcher S, Streiner D, Gratzer D, Kurdyak P, Yatham L. Population mental health and COVID19: why do we know so little? Can J Psychiatry. 2021:7067437211010523. https://doi.org/10.1177/07067437211 010523

2. Pierce M, McManus S, Jessop C, et al. Says who? The significance of sampling in mental health surveys during COVID-19. Lancet Psychiatry. 2020; 7(7):567-8. https://doi.org/10.1016 /S2215-0366(20)30237-6

3. Vaillancourt T, Brittain H, Krygsman $A$, et al. Assessing the quality of research examining change in children's mental health in the context of COVID-19. UOJM. 2021;11(1). https:// doi.org/10.18192/uojm.v11i1.5950

4. Statistics Canada. Survey on COVID19 and Mental Health (SCMH): detailed information for September to December 2020 [Internet]. Ottawa (ON): Statistics Canada; 2020 [cited 2021 May 25]. Available from: https://www23.statcan .gc.ca/imdb/p2SV.pl? Function $=$ getSurvey\&Id $=1283036$

5. Statistics Canada. Canadian Community Health Survey - Annual Component (CCHS): detailed information for 2019 [Internet]. Ottawa (ON): Statistics Canada; 2019 [cited 2021 May 25]. Available from: https://www23.statcan .gc.ca/imdb/p2SV.pl?Function $=$ getSurvey\&Id = 1208978

6. Capaldi CA, Liu L, Dopko RL. Positive mental health and perceived change in mental health among adults in Canada during the second wave of the COVID-19 pandemic. Health Promot Chronic Dis Prev Can. 2021;41(11): 359-77. https://doi.org/10.24095 /hpcdp.41.11.05

7. Hill MacEachern K, Venugopal J, Varin M, Weeks M, Hussain N, Baker MM. Applying a gendered lens to understanding self-reported changes in alcohol and cannabis consumption during the second wave of the COVID-19 pandemic in Canada, September to December 2020. Health Promot Chronic Dis Prev Can. 2021; 41(11):331-9. https://doi.org/10.24095 /hpcdp.41.11.03
8. Liu L, Capaldi CA, Dopko RL. Suicide ideation in Canada during the COVID19 pandemic. Health Promot Chronic Dis Prev Can. 2021;41(11):378-91. https://doi.org/10.24095/hpcdp.41 .11 .06

9. Shields M, Tonmyr L, Gonzalez A, et al. Symptoms of major depressive disorder during the COVID-19 pandemic: results from a representative sample of the Canadian population. Health Promot Chronic Dis Prev Can. 2021;41(11):340-58. https://doi.org /10.24095/hpcdp.41.11.04

10. Varin M, Hill MacEachern K, Hussain $\mathrm{N}$, Baker MM. Measuring self-reported change in alcohol and cannabis consumption during the second wave of the COVID-19 pandemic in Canada. Health Promot Chronic Dis Prev Can. 2021;41(11):325-30. https:// doi.org/10.24095/hpcdp.41.11.02

11. Pierce $\mathrm{M}$, Hope $\mathrm{H}$, Ford $\mathrm{T}$, et al. Mental health before and during the COVID-19 pandemic: a longitudinal probability sample survey of the UK population. Lancet Psychiatry. 2020; 7(10):883-92. https://doi.org/10.1016 /S2215-0366(20)30308-4

12. Pierce M, McManus S, Hope $\mathrm{H}$, et al. Mental health responses to the COVID-19 pandemic: a latent class trajectory analysis using longitudinal UK data. Lancet Psychiatry. 2021; 8(7):610-9. https://doi.org/10.1016 /S2215-0366(21)00151-6

13. Czeisler MÉ, Lane RI, Wiley JF, Czeisler CA, Howard ME, Rajaratnam SM. Follow-up survey of US adult reports of mental health, substance use, and suicidal ideation during the COVID-19 pandemic, September 2020. JAMA Netw Open. 2021;4(2):e2037665. https://doi.org/10.1001/jamanetwork open. 2020.37665

14. McGinty EE, Presskreischer R, Anderson KE, Han H, Barry CL. Psychological distress and COVID-19-related stressors reported in a longitudinal cohort of US adults in April and July 2020. JAMA. 2020;324(24):2555-7. https:// doi.org/10.1001/jama.2020.21231
15. McGinty EE, Presskreischer R, Han H, Barry CL. Psychological distress and loneliness reported by US adults in 2018 and April 2020. JAMA. 2020; 324(1):93-4. https://doi.org/10.1001 /jama.2020.9740

16. Aknin LB, DeNeve JE, Dunn EW, et al.; The Lancet's COVID-19 Commission Mental Health Task Force. Mental health during the first year of the COVID-19 pandemic: a review and recommendations moving forward. PsyArXiv [Preprint]. 2021 [cited 2021 Aug 19]. https://doi.org/10.31234/osf .io/zw93g

17. Racine N, McArthur BA, Cooke JE, Eirich R, Zhu J, Madigan S. Global prevalence of depressive and anxiety symptoms in children and adolescents during COVID-19: a meta-analysis. JAMA Pediatr. 2021:e212482. https:// doi.org/10.1001/jamapediatrics.2021 .2482

18. Sun Y, Wu Y, Bonardi O, et al. Comparison of mental health symptoms prior to and during COVID-19: evidence from a living systematic review and meta-analysis. medRxiv [Preprint]. 2021.05.10.21256920. https:// doi.org/10.1101/2021.05.10.21256920

19. Pirkis J, John A, Shin S, et al. Suicide trends in the early months of the COVID-19 pandemic: an interrupted time-series analysis of preliminary data from 21 countries. Lancet Psychiatry. 2021;8(7):579-88. https://doi.org/10 .1016/S2215-0366(21)00091-2

20. Benton TD, Boyd RC, Njoroge WF. Addressing the global crisis of child and adolescent mental health. JAMA Pediatr. 2021. https://doi.org/10.1001 /jamapediatrics.2021.2479

21. van Straten A, Hill J, Richards DA, Cuijpers P. Stepped care treatment delivery for depression: a systematic review and meta-analysis. Psychol Med. 2015;45(2):231-46. https://doi .org/10.1017/S0033291714000701

22. Ho FY, Yeung WF, Ng TH, Chan CS. The efficacy and cost-effectiveness of stepped care prevention and treatment for depressive and/or anxiety disorders: a systematic review and meta-analysis. Sci Rep. 2016;6:29281. https://doi.org/10.1038/srep29281 
23. Waddell C, Georgiades K, Duncan L, et al.; 2014 Ontario Child Health Study Team. 2014 Ontario Child Health Study findings: policy implications for Canada. Can J Psychiatry. 2019;64(4):227-31. https://doi.org/10 $.1177 / 0706743719830033$

24. Kurdyak P, Patten S. The burden of mental illness and evidence-informed mental health policy development. Can J Psychiatry. 2021:7067437211021299. https://doi.org/10.1177/070674372 11021299

25. Holmes EA, O’Connor RC, Perry VH, et al. Multidisciplinary research priorities for the COVID-19 pandemic: a call for action for mental health science. Lancet Psychiatry. 2020; 7(6):547-60. https://doi.org/10.1016 /S2215-0366(20)30168-1

26. Parmar D, Stavropoulou C, Ioannidis JP. Health outcomes during the 2008 financial crisis in Europe: systematic literature review. BMJ. 2016;354:1-11. https://doi.org/10.1136/bmj.i4588

27. Rajmil L, Fernandez de Sanmamed MJ, Choonara I, et al.; International Network for Research in Inequalities in Child Health (INRICH). Impact of the 2008 economic and financial crisis on child health: a systematic review. Int $\mathrm{J}$ Environ Res Public Health. 2014;11(6):6528-46. https:// doi.org/10.3390/ijerph110606528

28. Van Lancker W, Parolin Z. COVID-19, school closures, and child poverty: a social crisis in the making. Lancet Public Health 2020;5(5):e243-4. https:// doi.org/10.1016/S2468-2667(20)30084-0

29. Malilay J, Heumann M, Perrotta D, et al. The role of applied epidemiology methods in the disaster management cycle. Am J Public Health. 2014;104 (11):2092-102. https://doi.org/10.2105 /AJPH.2014.302010

30. Health Data Research UK. COVID-19 National Core Studies [Internet]. HDRUK; [cited 2021 Aug 19]. Available from: https://www.hdruk.ac.uk /covid-19/covid-19-national-core -studies/
31. Woelbert E, White R, Lundell-Smith $\mathrm{K}$, Grant J, Kemmer D. The inequities of mental health research funding [Internet]. Montreal (QC): International Alliance of Mental Health Research Funders; 2020 [cited 2021 Aug 16]. Available from: https://doi .org/10.6084/m9.figshare. 13055897 .$v 2$

32. Marmot M, Allen J, Goldblatt P, Boyce T, McNeish D, Grady M. Fair society, healthy lives: the Marmot review report: strategic review of health inequalities in England post2010. London (UK): Institute of Health Equity; 2010. https://www . instituteofhealthequity. org /resources-reports/fair-society -healthy-lives-the-marmot-review /fair-society-healthy-lives-full-report -pdf.pdf

33. Statistics Canada. Canadian Health Survey on Children and Youth (CHSCY). Ottawa (ON): Statistics Canada; 2020 [cited 2021 Aug 19]. Available from: https://www23 .statcan.gc.ca/imdb/p2SV.pl?Function $=$ getSurvey $\&$ SDDS $=5233$ 